\title{
2 Spatial variability in the hyporheic zone refugium of temporary streams
}

\author{
4 Rachel Stubbington • Paul J. Wood • \\ 5 Ian Reid
}

8 Abstract A key ecological role hypothesized for the 9 hyporheic zone is as a refugium that promotes survival of 10 benthic invertebrates during adverse conditions in the 11 surface stream. Many studies have investigated use of the 12 hyporheic refugium during hydrological extremes (spates 13 and streambed drying), and recent research has linked an 14 increase in the abundance of benthic invertebrates within 15 hyporheic sediments to increasing biotic interactions dur16 ing flow recession in a temporary stream. This study 17 examined spatial variability in the refugial capacity of the 18 hyporheic zone in two groundwater-dominated streams in 19 which flow permanence varied over small areas. Two non20 insect taxa, Gammarus pulex and Polycelis spp. were 21 common to both streams and were investigated in detail. 22 Hydrological conditions in both streams comprised a four23 month period of flow recession and low flows, accompa24 nied by reductions in water depth and wetted width. 25 Consequent declines in submerged benthic habitat avail26 ability were associated with increases in population 27 densities of mobile benthic taxa, in particular G. pulex. The 28 reduction in the spatial extent of the hyporheic zone was 29 minimal, and this habitat was therefore a potential refu30 gium from increasing biotic interactions in the benthic
This article belongs to the Special Issue "Recent Perspectives on Temporary River Ecology".

\section{R. Stubbington $(\triangle \Delta)$}

School of Science and Technology, Nottingham Trent

University, Clifton Campus, Nottingham,

Nottinghamshire NG11 8NS, UK

e-mail: rachel.stubbington@ntu.ac.uk

P. J. Wood · I. Reid

Department of Geography, Loughborough University, Loughborough, Leicestershire LE11 3TU, UK sediments. Concurrent increases in the hyporheic abundance and hyporheic proportion of a taxon's total (benthic + hyporheic) population were considered as evidence of active refugium use. Such evidence was speciesspecific and site-specific, with refugium use being observed only for $G$. pulex and at sites dominated by downwelling water. A conceptual model of spatial variability in the refugial capacity of the hyporheic zone during habitat contraction is presented, which highlights the potential importance of the direction of hydrologic exchange.

Keywords Hyporheic refuge hypothesis - Low flows · Habitat contraction · Hyporheos - Benthos - Gammarus

\section{Introduction}

Refugia are places where organisms have an increased probability of surviving a disturbance event, due to relatively low disturbance impacts (Lancaster and Belyea 1997). In lotic ecosystems, the hyporheic zone (HZ) has been demonstrated to act as a refugium that promotes persistence of invertebrates during adverse conditions in the surface (benthic) sediments (Orghidan 1959, 2010; Williams and Hynes 1974; Robertson and Wood 2010). Research examining the $\mathrm{HZ}$ as a refugium has focussed on the extremes of the hydrological continuum, namely spates and streambed drying (Boulton and Stanley 1995; Dole-Olivier et al. 1997), and this refuge is therefore of particular relevance for the persistence of temporary stream communities. Several studies have inferred active invertebrate migrations into the $\mathrm{HZ}$ as the water table falls below the sediment surface (Cooling and Boulton 1993; Clinton et al. 1996) whilst others have noted passive refugium use following streambed drying (Del Rosario and Resh 2000;

\begin{tabular}{|l|lll|}
\hline & Journal : Large 27 & Dispatch : 10-4-2011 & Pages : 13 \\
Article No. : 203 & $\square \mathrm{LE}$ & $\square$ TYPESET \\
MS Code : AOSC511 & $\sim_{\mathrm{CP}}$ & DISK $^{2}$ \\
\hline
\end{tabular}


64 Fenoglio et al. 2006). However, evidence for the hyporheic 65 refuge hypothesis (Williams and Hynes 1974) during dry66 ing is equivocal, with many studies finding that few benthic 67 taxa actively exploit the HZ (Boulton 1989; Boulton and 68 Stanley 1995; Belaidi et al. 2004).

These contrasting reports suggest that the $\mathrm{HZ}$ must fulfil certain criteria in order to function as a refuge, with some studies attributing a lack of refugium use to a single factor such as anoxia (Smock et al. 1994) or the loss of interstitial free water (Boulton and Stanley 1995) following surface drying. The importance of hydrologic exchange has also been highlighted, with downwelling water facilitating migrations into deeper sediments (Dole-Olivier et al. 1997). Sediment composition is also an influential determinant of hyporheic community composition, with a high proportion of fine sediment (variously defined as $<150 \mu \mathrm{m}$ (Richards and Bacon 1994), <1 mm (Olsen and Townsend 2005) and $<2 \mathrm{~mm}$ (Weigelhofer and Waringer 2003)) reducing inhabitable space (Belaidi et al. 2004; Olsen and Townsend 2005). Considering the heterogeneity of instream habitats (Winemiller et al. 2010), refugium use is likely to vary over small areas depending on the character of the hyporheic sediments (Lancaster and Belyea 1997).

Little research has considered the $\mathrm{HZ}$ refugium during flow recession and low flows, despite their inevitable occurrence prior to the dry phase in temporary streams. As discharge decreases, submerged habitats contract and topographic high points become exposed (Cowx et al. 1984; Dewson et al. 2003). Reduced submerged habitat availability typically concentrates mobile invertebrates into smaller areas, with many studies noting increasing benthic population densities as flow declines (Fritz and Dodds 2004; James et al. 2008). Many biotic interactions are density dependent and increasing population densities may intensify competition, predation and cannibalism (Savage 1996; Covich et al. 2003; Holomuzki et al. 2010).

The $\mathrm{HZ}$ may act as a refugium from biotic interactions, due to lower population densities when compared with the benthic sediments (Williams and Hynes 1974;
Davy-Bowker et al. 2006). The $\mathrm{HZ}$ is recognised as a nursery which reduces predation on vulnerable invertebrates such as early instar insect larvae (Puig et al. 1990). Experimental work has also demonstrated that Gammarus pulex (Amphipoda: Crustacea) may migrate into smaller interstices in response to an increase in intraspecific predation (McGrath et al. 2007). In addition, one field study has linked submerged habitat contraction and an increase in benthic population densities to migrations into the $\mathrm{HZ}$ (Stubbington et al. 2011). In contrast, other studies have recorded no increase in the hyporheic abundance of benthic taxa in response to flow reduction (James et al. 2008; Stubbington et al. 2009a; Wood et al. 2010). Such inconsistent reports emphasize the potential importance of spatially variable habitat parameters in determining benthic invertebrate use of the $\mathrm{HZ}$. In the current study, spatial variation in the use of the $\mathrm{HZ}$ refuge during flow recession and low flows was examined in two temporary streams in relation to three hyporheic habitat parameters: the direction of hydrologic exchange, oxygen availability and sediment composition.

\section{Methods}

Study location

Two temperate-zone groundwater-dominated streams were investigated (Fig. 1). The River Lathkill (Derbyshire, UK; $53^{\circ} 11.2^{\prime} \mathrm{N}, 1^{\circ} 43.1^{\prime} \mathrm{W}$ ) is a 2 nd order stream which flows for $8.5 \mathrm{~km}$ through an incised valley, the sides of which are vegetated by deciduous woodland. The River East Glen (Lincolnshire, UK; $52^{\circ} 45.9^{\prime} \mathrm{N},-0^{\circ} 25.8^{\prime} \mathrm{E}$ ) is a $3 \mathrm{rd}$ order stream flowing for $37 \mathrm{~km}$ through a predominantly agricultural catchment. The Lathkill receives mean monthly rainfall of between $58 \mathrm{~mm}$ in August and $136 \mathrm{~mm}$ in December (1991-2000 mean; British Atmospheric Data Centre (BADC) 2009), has a mean annual temperature of $8^{\circ} \mathrm{C}$, with temperatures peaking in July (Wood et al. 2005). The Glen catchment is drier and seasonal differences in
Fig. 1 Location maps and flow regimes of the River Lathkill and River Glen

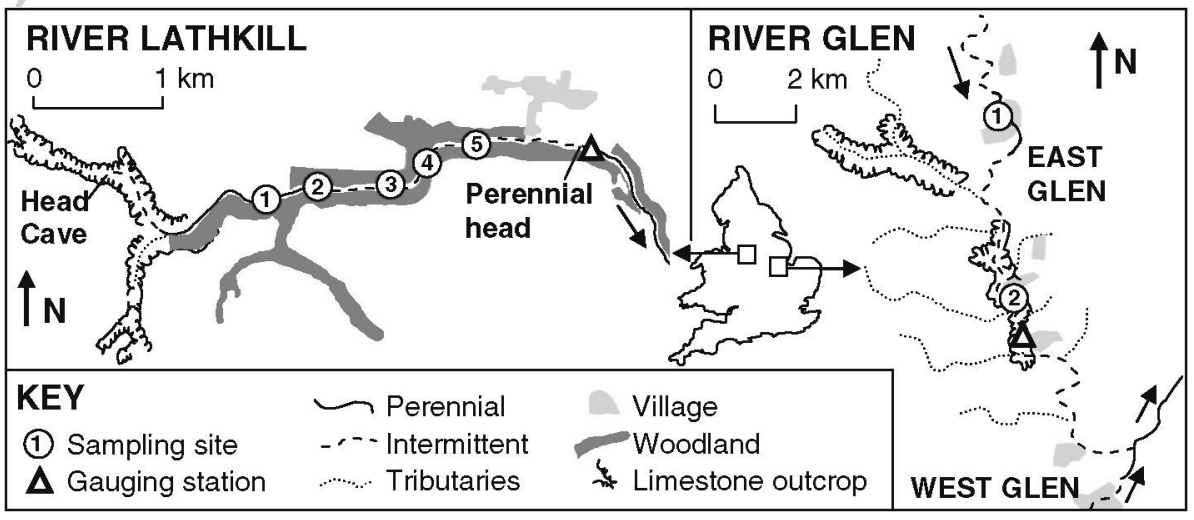

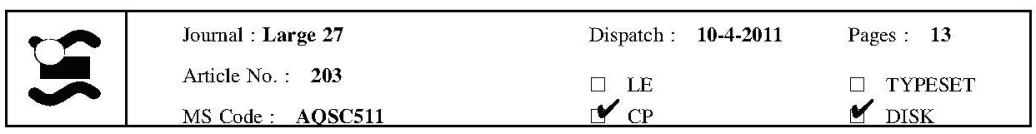


rainfall are less pronounced, with mean values ranging from $36 \mathrm{~mm}$ in February to $61 \mathrm{~mm}$ in October (1980-2008 mean; British Atmospheric Data Centre (BADC) 2009). The region has a mean annual temperature of $10.5^{\circ} \mathrm{C}$, with the highest temperatures occurring in July and August (Met Office 2009). Reaches of both rivers typically dry during summer, partly due to natural features of the underlying karst aquifers (Maddock et al. 1995; Stubbington et al. $2009 \mathrm{~b}$ ). In the Lathkill, this loss of flow is exacerbated in some reaches by underlying disused mine drainage soughs, whilst losses on the Glen are increased by abstractions for public water supply. Upwelling groundwater sustains perennial flow in other reaches of both rivers.

Seven sites (designated Lathkill 1-5 and Glen 1-2) were selected on the two rivers to characterise spatial variability in the flow regime (Fig. 1). On the Lathkill, two sites have perennial flow (Lathkill 1-2) and three sites typically dry during the summer (Lathkill 3-5). On the Glen, one perennial site (Glen 1) and one intermittent site (Glen 1) were investigated. In both rivers, the substrate consists predominantly of cobble and pebble gravels, although clast sizes range from silt to boulder. During the study, phytobenthos was dominated by bryophytes in the Lathkill, whilst filamentous algae were abundant in the Glen; emergent reeds were also present in marginal areas of both rivers.

\section{Hydrological conditions}

During the study period (May-September 2008), flow recession in the Lathkill proceeded uninterrupted from May until August (Fig. 2a), although above-average precipitation resulted in surface flow remaining connected throughout the study area. Discharge then increased considerably in late August following heavy rainfall. On the Glen, a series of rain-fed low-magnitude flow increases occurred between May and June sampling. Discharge then declined, culminating in streambed drying at Glen 2 in late July and early September, with surface flow returning briefly between drying events (Fig. 2b).
Field sampling

The seven sites were sampled at monthly intervals over a 5 month period from May to September 2008, with the exception of Lathkill 5, which was inaccessible in the first month of the study. However, only flow recession and low flows are of relevance to the current investigation, and, therefore, data collected from the Lathkill between May and August and from the Glen between June and September are presented. These months are referred to as months $1-4$ in combined analyses of both rivers.

Four sampling points were selected at each site to reflect the prevailing instream conditions. At each sampling point, three open-ended polyvinylchloride (PVC) pipes $(19 \mathrm{~mm}$ internal diameter) were driven into the substrate using a stainless steel T-bar (Boulton and Stanley 1995; Wood et al. 2010). These pipes functioned as permanent hyporheic invertebrate sampling wells for the duration of the study. Pipes were inserted to depths of 10,20 and $30 \mathrm{~cm}$, respectively, and were positioned $\geq 0.5 \mathrm{~m}$ apart to minimise any influence of sampling in one well on the sediments sampled by adjacent wells. Each well was sealed between sampling occasions to prevent sediment deposition and colonisation by benthic invertebrates. Each month, $6 \mathrm{~L}$ of water were extracted from the base of each sampling well using a hand-operated bilge pump and passed through a $125 \mu \mathrm{m}$ sieve to retain macroinvertebrates (e.g. Boulton and Stanley 1995).

Due to the inaccessibility of hyporheic habitat, all invertebrate sampling techniques have significant limitations (Palmer 1993). Manual pump sampling, for example, favours the collection of smaller, less tenacious invertebrates (Fraser and Williams 1997) and sampling efficiency varies with sediment hydraulic conductivity (Scarsbrook and Halliday 2002). However, pump sampling causes minimal disturbance to the sediments and therefore allows repeated collection of quantitative samples from the same location during a temporal sequence, which was essential in the current study (see Stubbington et al. 2009a). Other quantitative methods (e.g. coring, colonisation pots) do not
Fig. 2 Hydrographs of: a mean hourly discharge on the River Lathkill, April-August 2008; b mean 15-min discharge on the River Glen, May-September 2008. Arrows indicate sampling dates. Location of gauging stations shown in Fig. 1
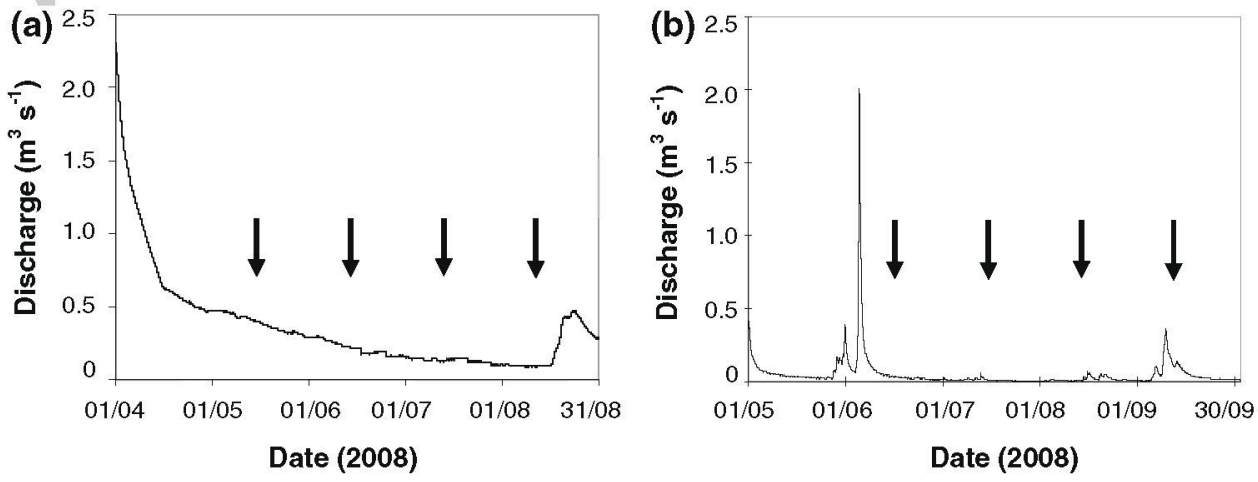

\begin{tabular}{|c|c|c|c|c|}
\hline & Journal : Large 27 & Dispatch : & 10-4-2011 & Pages: 13 \\
\hline & $\begin{array}{l}\text { Article No. : } 203 \\
\text { MS Code : AOSC511 }\end{array}$ & $\begin{array}{l}\square \mathrm{LE} \\
\boldsymbol{V}_{\mathrm{CP}} \\
\end{array}$ & & $\begin{array}{l}\square \text { TYPESET } \\
\checkmark \text { DISK } \\
\end{array}$ \\
\hline
\end{tabular}


fulfil this criterion and were therefore unsuitable. In addition, several previous studies have demonstrated the ability of pump sampling to characterise changes in hyporheic community composition in response to hydrological variability and flow permanence (e.g. Boulton and Stanley 1995; Hancock 2006; Datry et al. 2007).

Invertebrates were collected from the benthic sediments above each set of hyporheic sampling wells using a standard Surber sampler $\left(0.1 \mathrm{~m}^{2}, 1 \mathrm{~mm}\right.$ mesh net), by manually disturbing the substrate within the frame to a depth of $\sim 5 \mathrm{~cm}$ for $30 \mathrm{~s}$. The current study analysed only macroinvertebrate fauna (body size $>1 \mathrm{~mm}$ ), and therefore the different mesh sizes used to sample benthic and hyporheic sediments is not of relevance.

To assess the effects of discharge variability on habitat availability, water depth was measured at each sampling point. Wetted width was then determined by applying depth measurements to cross-sectional profiles generated using standard tacheometric survey data. To assess the suitability of the $\mathrm{HZ}$ as an invertebrate refugium, hyporheic dissolved oxygen concentrations (DO, $\mathrm{mg} \mathrm{L}^{-1}$ ), the direction of hydrologic exchange and sediment composition were examined. DO was measured in situ using standard instrumentation (Hanna Instruments, Leighton Buzzard, UK). The direction of hydrologic exchange was estimated using mini-piezometers, consisting of a pair of open-ended PVC pipes (19 mm internal diameter), one perforated with $2 \mathrm{~mm}$ holes and the other intact. These pipes were positioned $\sim 20 \mathrm{~cm}$ apart and were inserted to a depth of $30 \mathrm{~cm}$, as described for hyporheic sampling wells. The tops of the mini-piezometers were left protruding several $\mathrm{cm}$ above the expected highest water level. This equipment was clearly visible, resulting in unacceptable impacts on visual amenity at Lathkill 1; this site was therefore not instrumented. Each month, an electronic dipstick was inserted into each pair of mini-piezometers and the two water levels compared to provide an indication of the direction of hydrologic exchange. At some sampling points, water did not refill the intact mini-piezometer; this suggested strongly downwelling water, but was also potentially due to sediment clogging (Boulton 2007). Measurements were therefore supplemented by other information, including on-site observations, water temperature and water chemistry data, and the typical flow permanence regime. After completion of the sampling programme, sediments were collected using a McNeil sampler to characterise bulk sediment composition to a depth of $25 \mathrm{~cm}$ (following Bunte and Abt 2001).

\section{Laboratory procedures}

Invertebrates were identified to the lowest taxonomic resolution possible, in many cases species level, but groups including the Oligochaeta were left at a higher taxonomic level. Sediment samples were oven dried at $105^{\circ} \mathrm{C}$ until a constant weight was recorded, gently disaggregated, then dry-sieved through a sieve nest $(8,4,2$, and $1 \mathrm{~mm}, 500$, $250,125$ and $63 \mu \mathrm{m})$ and each fraction weighed to determine the grain size distribution. To reduce the influence of large particles on the calculated percentage of fine sediment, clasts with an $a$-axis $>75 \mathrm{~mm}$ were excluded (following Rice 1995).

\section{Data analysis}

Changes in environmental variables (surface water depth, wetted width, DO) were analysed using repeated measures (RM) ANOVA. Two-way RM ANOVA with site as a between-subjects factor was used to determine the significance of spatial differences and the interaction with site. One-way RM ANOVA was used to examine temporal variability at all sites combined and, where a significant interaction with site had been identified, at individual sites. For all RM ANOVA tests, where the assumption of sphericity was violated, Greenhouse-Geisser tests were used to determine significance. Benthic and hyporheic data were analysed separately, whilst preliminary RM ANOVA tests indicated comparable patterns of temporal change at the three hyporheic depths, and all were therefore pooled.

Water depth data were applied to cross-sectional channel profiles to determine the area of submerged habitat available each month. At most sites, a single cross-section was considered representative of conditions at all sampling points, whilst depth data were applied to two Lathkill 4 cross-sections ((1) and (2) in Table 1) due to longitudinal variation in bed morphology.

The abundance of common benthic taxa $(>1 \%$ of all invertebrates present in Surber samples) was determined separately for benthic and hyporheic habitats. Preliminary analysis showed comparable patterns of variability in community composition at the three hyporheic depths, and

Table 1 Temporal change in extent of submerged benthic sediments as a percentage of the maximum recorded

\begin{tabular}{|c|c|c|c|c|c|c|c|c|}
\hline \multirow[t]{3}{*}{ Month $^{\mathrm{a}}$} & \multicolumn{8}{|c|}{ Submerged $\%$ of benthic sediments } \\
\hline & \multicolumn{6}{|c|}{ River Lathkill sites } & \multicolumn{2}{|c|}{ River Glen sites } \\
\hline & 1 & 2 & 3 & $4(1)^{b}$ & $4(2)^{b}$ & 5 & 1 & 2 \\
\hline 1 & 100 & 100 & 100 & 100 & 100 & 100 & 100 & 90 \\
\hline 2 & 40 & 42 & 35 & 48 & 97 & 100 & 81 & 23 \\
\hline 3 & 58 & 42 & 29 & 100 & 100 & 94 & 81 & 100 \\
\hline 4 & 34 & 23 & 17 & 31 & 84 & 20 & 53 & 90 \\
\hline
\end{tabular}

${ }^{a}$ Month 1-4 = May-August 2008 on the Lathkill and June-September 2008 on the Glen

${ }^{\mathrm{b}}$ Bracketed numbers refer to sampling areas

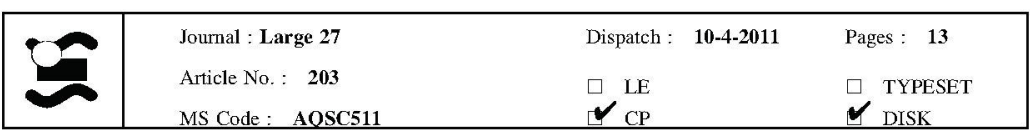




\section{Results}

all were therefore pooled. Insect taxa were excluded from analyses due to the confounding influence of seasonal adult emergence. Taxa identified to group level and likely to include multiple representatives (e.g. the Oligochaeta) were also excluded, to avoid inaccurate inference of ecological patterns (Datry et al. 2010). To investigate use of the $\mathrm{HZ}$ by selected individual benthic taxa, the number of individuals present in the $\mathrm{HZ}$ was divided by the total (benthic + hyporheic) number of individuals recorded, to determine the hyporheic proportion of the taxon's population. Proportional data facilitates comparison of populations sampled using different methods. Abundance data were square-root transformed and proportions arcsine square-root transformed prior to subsequent analysis. Transformed metrics were used as dependent variables in RM ANOVA tests to examine spatial and temporal variability in invertebrate distribution, as outlined for environmental data.

Temporal change in the submerged benthic habitat area was calculated between months $1-2,2-3$ and $3-4$, with area in the latter month being described as a $\%$ of that recorded in the former. Scatter plots were then used to investigate relationships between monthly variation in habitat availability and concurrent \% changes in invertebrate abundance. Benthic and hyporheic abundances were considered both separately and simultaneously. Pearson's correlation coefficients were then calculated to examine the strength and significance of relationships.

\section{Availability of submerged benthic habitat}

Considering all sites, reductions in both water depth $\left(F_{3,63}=59.014, p<0.001\right)$ and wetted width $\left(F_{1.339,6.694}=\right.$ $45.416, p<0.001$ ) were significant between months 1 and 4 . The interaction with site was also significant for both depth $\left(F_{18,63}=9.021, p<0.001\right)$ and width $\left(F_{8.032,6.694}=12.671\right.$, $p=0.002$ ), and the extent and timing of reductions in submerged habitat availability were site-specific (Table 1). Habitat availability was highest in month 1 and lowest in month 4 at all sites except Glen 2, where the submerged area was particularly low in month 2 (Table 1 ).

\section{Invertebrate abundance in the benthic sediments}

The Lathkill community was dominated by Gammarus pulex $(40.8 \%$ of total invertebrate abundance (TIA)); Polycelis felina (Turbellaria: Planariidae; $6.8 \%$ TIA) and the Oligochaeta ( $4.9 \%$ TIA) were also common. In the Glen, oligochaetes were the dominant non-insect taxon (17.3\% TIA); other common taxa ( $>1 \%$ TIA) included
Hydracarina, G. pulex, Asellus aquaticus and Polycelis tenuis. Suitable taxa which were sufficiently abundant in both rivers to justify detailed analysis therefore comprised G. pulex and Polycelis spp.

Considering all sites, mean $G$. pulex abundance increased significantly from month 1 (54 \pm 9 individuals $\left.0.1 \mathrm{~m}^{-2}\right)$ to month $4\left(166 \pm 36\right.$ individuals $0.1 \mathrm{~m}^{-2}$; Fig. 3a; Table 2). Abundance also varied spatially, being highest at Lathkill 1 and lowest at Glen 1 (Fig. 3a; Table 2). The interaction with site was also significant (Table 2) and site-specific patterns of temporal change were significant at Lathkill 1, Lathkill 4 and Glen 2 (Fig. 3a). Mean Polycelis spp. abundance was low in month $1\left(4.7 \pm 1.3\right.$ individuals $\left.0.1 \mathrm{~m}^{-2}\right)$ and significantly higher in later months $\left(\geq 19.7 \pm 8.3\right.$ individuals $0.1 \mathrm{~m}^{-2}$; Fig. 4a; Table 2). Spatially, the taxon was particularly abundant at Lathkill 1 and virtually absent from Lathkill 3-5 and Glen 1 (Table 2). The interaction with site was significant (Table 2) and abundance was sufficiently high at Lathkill 1 and 2 and Glen 2 to justify further analysis. The overall pattern of temporal change was observed at Lathkill 1 and 2, whilst at Glen 2, abundance peaked in month 2 and was very low in later months (Fig. 4a).

Spatial variability in hyporheic habitat

Whilst the reduction in submerged habitat availability was widespread in the benthic sediments, on-site observations indicated that the extent of the submerged $\mathrm{HZ}$ was largely unaltered, free water being present at a depth of $10 \mathrm{~cm}$ in all cases. However, DO concentrations, the direction of hydrologic exchange, and sediment composition may have affected the HZ's ability to function as a refugium.

RM ANOVA of hyporheic DO concentrations includes data collected between months 2 and 4 at Lathkill 1-5 and Glen 1, due to missing values in the month 1 and Glen 2 datasets. However, the available data indicate that DO concentrations were highest in month 1 ; a subsequent gradual reduction between months 2 and 4 was significant (Table 3). Considering all months, concentrations varied between sites $\left(F_{5,66}=8.666, p<0.001\right)$, being highest at Lathkill 2 and low at Lathkill 1 and Glen 1; individual readings indicated lower mean values at Glen 2 (Table 3). The interaction between DO and site was significant $\left(F_{9.953,131.381}=22.655, p<0.001\right)$ and patterns of temporal change were site-specific (Table 3 ).

The direction of hydrologic exchange at Lathkill 1 was strongly upwelling: rheocrene springs are present at the site margins, upwelling water was directly observed in sampling wells, and both surface and hyporheic water had distinctive qualities indicative of groundwater (high conductivity and low temperature). Upwelling water was also consistently recorded in mini-piezometers at Glen 1 . In

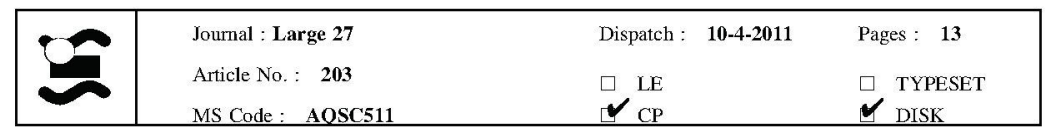




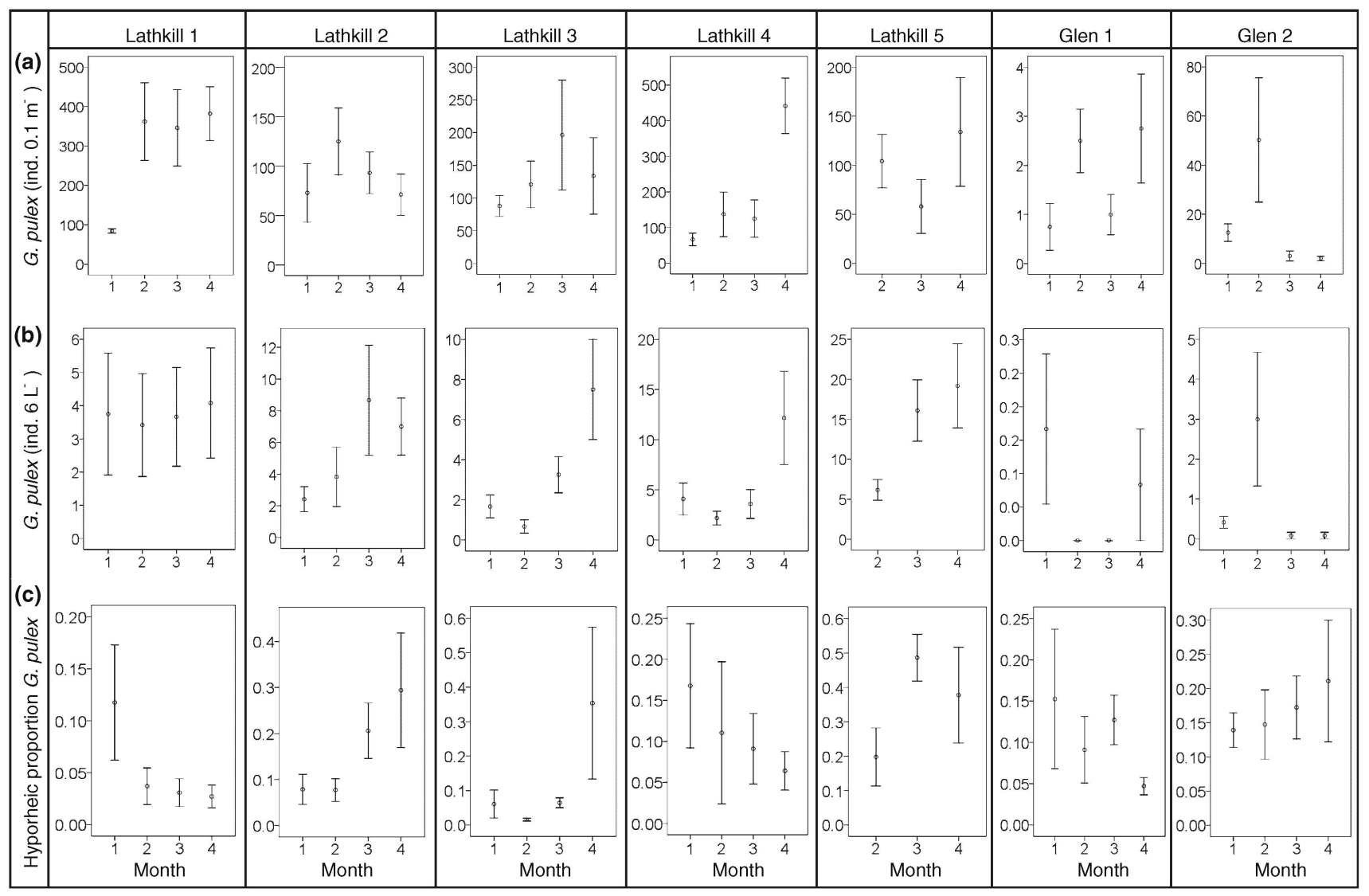

Fig. 3 Mean \pm 1 SE Gammarus pulex at sites 1-5 on the River Lathkill and sites 1-2 on the River Glen: a benthic abundance (individuals $0.1 \mathrm{~m}^{-2}$ ); b hyporheic abundance (individuals $6 \mathrm{~L}^{-1}$ );

and c hyporheic proportion of the total (benthic + hyporheic) population. Months 1-4 are May-August 2008 on the Lathkill and June-September 2008 on the Glen

Table 2 Temporal and spatial change in invertebrate occurrence in the benthic and hyporheic zones of the River Lathkill and River Glen

\begin{tabular}{|c|c|c|c|c|c|c|}
\hline \multirow[t]{2}{*}{ Taxon } & \multicolumn{2}{|c|}{ Temporal change ${ }^{\mathrm{a}}$} & \multicolumn{2}{|c|}{ Spatial change $^{\mathrm{a}}$} & \multicolumn{2}{|c|}{ Interaction $^{\mathrm{a}}$} \\
\hline & $F$ ratio & $p$ & $F$ ratio & $p$ & $F$ ratio & $p$ \\
\hline \multicolumn{7}{|l|}{ Benthic abundance } \\
\hline Gammarus pulex & 3.6 & 0.025 & 50.9 & $<0.001$ & 2.9 & 0.008 \\
\hline Polycelis felina & 3.0 & 0.073 & 10.9 & $<0.001$ & 7.5 & $<0.001$ \\
\hline \multicolumn{7}{|c|}{ Hyporheic abundance } \\
\hline G. pulex & 3.9 & 0.012 & 11.4 & $<0.001$ & 2.6 & 0.001 \\
\hline P. felina & 4.2 & 0.019 & 15.3 & $<0.001$ & 3.5 & $<0.001$ \\
\hline \multicolumn{7}{|c|}{ Hyporheic proportion } \\
\hline G. pulex & 3.4 & 0.048 & 5.9 & 0.001 & 1.6 & 0.102 \\
\hline P. felina & & 0.212 & 1.2 & 0.355 & 5.1 & 0.004 \\
\hline
\end{tabular}

${ }^{a}$ Significance determined using RM ANOVA; see text for further details

400 contrast, mini-piezometer data, physicochemical data and 401 an intermittent flow regime indicated the prevalence of 402 downwelling water at Lathkill 3-5 and Glen 2. At Lathkill 2, 403 evidence of both upwelling water (perennial flow and 404 obligate groundwater taxa in the HZ) and downwelling 405 water (mini-piezometer readings and water physicochem406 istry) was recorded.
For the purposes of summarising refugial potential (Table 4), fine sediment was defined following Olsen and Townsend (2005) as $<1 \mathrm{~mm}$; preliminary analyses had also indicated that this measure was most strongly correlated with community metrics. The percentage of fine sediment was lowest $(<16 \%)$ at Lathkill $1-3$ and exceeded $25 \%$ at all other sites (Table 4$)$. The highest

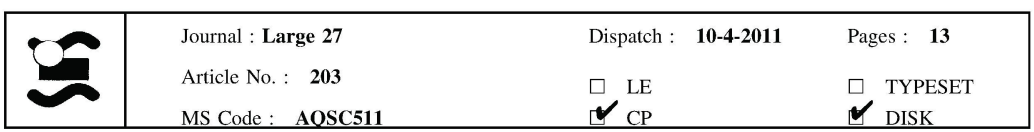


Fig. 4 Mean \pm 1 SE Polycelis felina at sites $1,2,4$ and 5 on the River Lathkill: a benthic abundance (individuals $0.1 \mathrm{~m}^{-2}$ ); b hyporheic

abundance (individuals $6 \mathrm{~L}^{-1}$ ); and $\mathbf{c}$ hyporheic proportion of the total (benthic + hyporheic) population. Months $1-4$ are May-August 2008

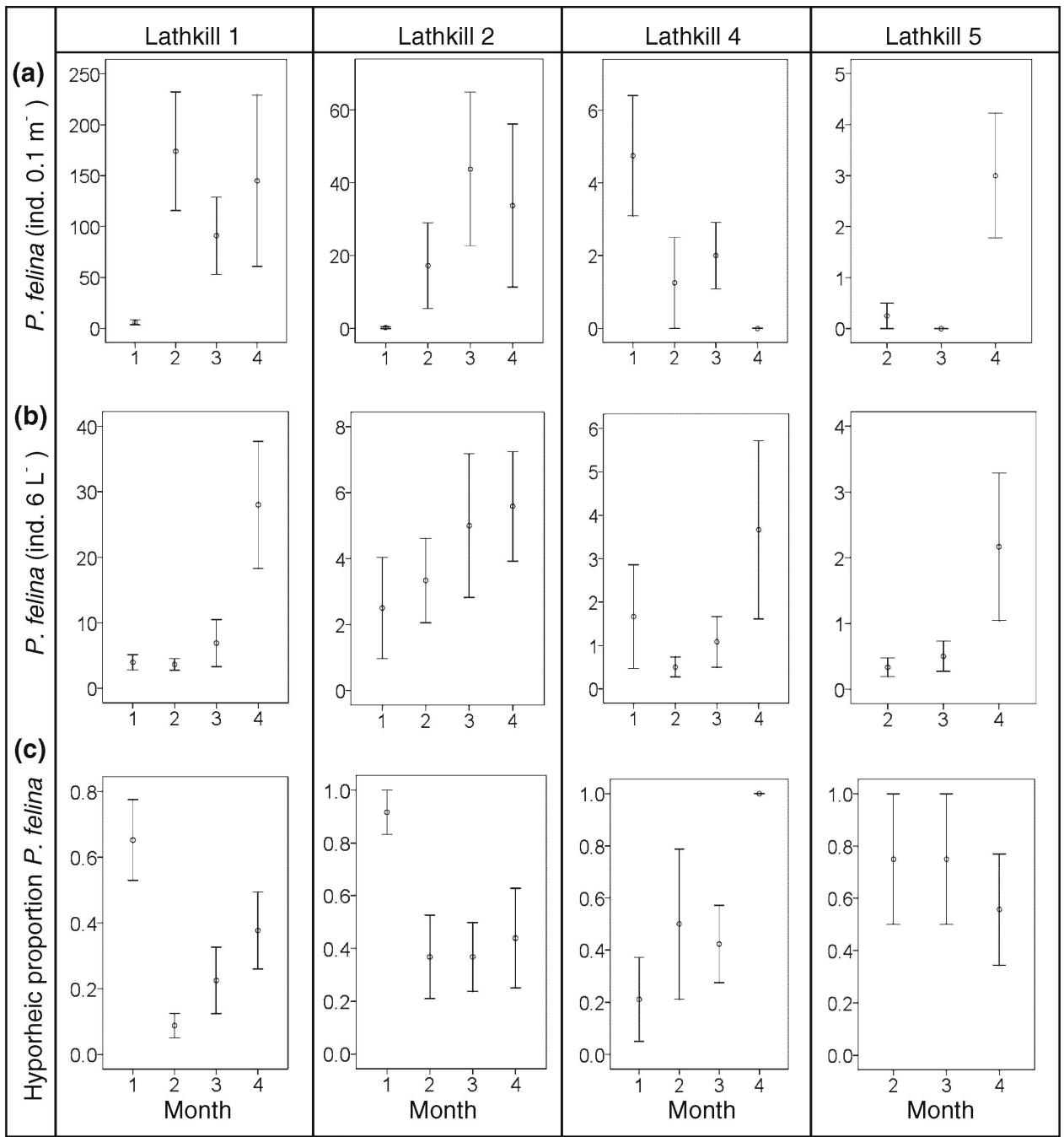

Table 3 Temporal change in hyporheic dissolved oxygen concentrations at sites on the River Lathkill and River Glen

\begin{tabular}{|c|c|c|c|c|c|c|c|}
\hline & & \multicolumn{4}{|c|}{ Mean \pm 1 SE dissolved oxygen concentration $\left(\mathrm{mg} \mathrm{L}^{-1}\right)$} & \multicolumn{2}{|c|}{ Temporal change ${ }^{\mathrm{a}}$} \\
\hline & & Month $1^{\mathrm{b}}$ & Month $2^{\mathrm{b}}$ & Month $3^{\mathrm{b}}$ & Month $4^{\mathrm{b}}$ & $F$ ratio & $p$ \\
\hline \multirow[t]{5}{*}{ Lathkill sites } & 1 & $7.3 \pm$ & $6.1 \pm 0.1$ & $4.8 \pm 0.2$ & $4.1 \pm 0.2$ & 18.1 & $<0.001$ \\
\hline & 2 & N/A & $5.5 \pm 0.4$ & $10.9 \pm 0.5$ & $5.1 \pm 0.4$ & 118.7 & $<0.001$ \\
\hline & 3 & $9.5 \pm$ & $7.7 \pm 0.5$ & $5.0 \pm 0.3$ & $5.5 \pm 0.4$ & 29.1 & $<0.001$ \\
\hline & 4 & N/A & $7.6 \pm 0.4$ & $6.7 \pm 0.7$ & $7.4 \pm 0.5$ & 2.6 & 0.099 \\
\hline & 5 & N/A & $6.8 \pm 0.3$ & $6.8 \pm 0.3$ & $4.0 \pm 0.7$ & 12.0 & 0.002 \\
\hline \multirow[t]{2}{*}{ Glen sites } & 1 & $6.6 \pm 0.5$ & $5.6 \pm 0.6$ & $2.6 \pm 0.6$ & $4.8 \pm 0.8$ & 17.3 & $<0.001$ \\
\hline & 2 & N/A & $2.9 \pm 0.6$ & $2.0 \pm 0.6$ & N/A & 2.6 & 0.132 \\
\hline All sites & & $7.3 \pm 0.3$ & $6.0 \pm 0.2$ & $5.6 \pm 0.4$ & $5.1 \pm 0.2$ & 9.9 & $<0.001$ \\
\hline
\end{tabular}

N/A data not available

${ }^{\text {a }}$ Significance determined using one-way RM ANOVA

${ }^{\mathrm{b}}$ Month 1-4 = May-August 2008 on the Lathkill and June-September 2008 on the Glen; $n=12$, except at Lathkill 3 in month 1 and at Lathkill 5 in month 2 , where $n=3$

414 percentage was recorded at Glen 1, where on-site 415 observations also indicated the presence of clay layers 416 in the substrate stratigraphy (Table 4). In addition, quantities of fines may have been underestimated at Glen 1 due to aggregation of silt and clay particles during oven drying.
417

\begin{tabular}{|c|c|c|c|c|}
\hline & Journal : Large 27 & Dispatch & 10-4-2011 & Pages: 13 \\
\hline & $\begin{array}{l}\text { Article No. : } 203 \\
\text { MS Code : } \quad \operatorname{AOSC511}\end{array}$ & $\begin{array}{l}\square \mathrm{LE} \\
\boldsymbol{V}_{\mathrm{CP}}\end{array}$ & & $\begin{array}{l}\square \text { TYPESET } \\
\downarrow_{\text {DISK }} \\
\end{array}$ \\
\hline
\end{tabular}


Table 4 Spatial variability in environmental determinants of the hyporheic zone's refugial potential

\begin{tabular}{lllll}
\hline River & Site & Hydrologic exchange & DO & Fine sediment $^{\mathrm{a}}$ \\
\hline Lathkill & 1 & Strongly upwelling & $4.1 \pm 0.2$ & $11.9 \pm 1.8$ \\
& 2 & Up- and downwelling & $5.1 \pm 0.4$ & $15.7 \pm 4.3$ \\
& 3 & Downwelling & $5.5 \pm 0.4$ & $13.8 \pm 4.0$ \\
& 4 & Downwelling & $7.4 \pm 0.5$ & $25.1 \pm 2.4$ \\
& 5 & Downwelling & $4.0 \pm 0.7$ & $28.4 \pm 2.2$ \\
Glen & 1 & Upwelling & $4.8 \pm 0.8$ & $33.1 \pm 8.5^{\mathrm{b}}$ \\
& 2 & Downwelling & $2.8 \pm 0.6$ & $27.0 \pm 2.0$ \\
\hline
\end{tabular}

DO hyporheic dissolved oxygen $\left(\mathrm{mg} \mathrm{L}^{-1}\right.$; mean $\pm 1 \mathrm{SE}$ in month of lowest habitat availability; $n=12$ )

${ }^{\mathrm{a}}$ Fine sediment (mean $\pm 1 \mathrm{SE}$ proportion of sediments $<1 \mathrm{~mm}$ )

${ }^{\mathrm{b}}$ Presence of clay layers; $n=2-4$

Benthic invertebrates in the hyporheic zone

421 The two non-insect taxa investigated in the benthic sedi422 ments (G. pulex and Polycelis spp.) were also common in the $\mathrm{HZ}$, and the hyporheic abundance and hyporheic proportion of the population was therefore calculated for both taxa. Spatially, G. pulex was most abundant in the $\mathrm{HZ}$ at Lathkill 5, whilst abundance was particularly low at both Glen sites (Fig. 3b; Table 2). The hyporheic proportion was also highest at Lathkill 5, and was lowest at Lathkill 1 (Fig. 3c; Table 2). Considering all sites, the hyporheic abundance of G. pulex more than trebled between months 1 and 4 (Fig. 3b; Table 2), this increase being accompanied by a rise in the hyporheic proportion of the population (Fig. 3c; Table 2). The interaction with site was significant for hyporheic abundance but not for the hyporheic proportion (Table 2), although spatially variable patterns were apparent in both metrics (Fig. 3b, c).

Polycelis spp. were particularly abundant in the $\mathrm{HZ}$ at Lathkill 1, whilst few individuals occurred at Lathkill 3 and Glen 1-2 (Fig. 4b; Table 2); the latter three sites were therefore excluded from further analysis. The hyporheic proportion of the population was comparable at the remaining four sites (Lathkill 1, 2, 4 and 5; Fig. 4c). The hyporheic abundance of Polycelis spp. at Lathkill 1, 2, 4 and 5 was lowest in months 1 and 2, increased slightly in month 3 then peaked in month 4 (Fig. 4b; Table 2). However, the hyporheic proportion of the Polycelis population remained stable in all months at these sites (Fig. 4c; Table 2). The interaction with site was significant for both abundance and proportion (Fig. 4b, c; Table 2).

Relationships between invertebrate abundance and habitat availability

Negative correlations were recorded between the $\%$ change in submerged benthic habitat and the \% change in the abundance of both G. pulex (Pearson's correlation coefficient $=-0.380, p=0.016$ ) and Polycelis spp. (Pearson's correlation coefficient $=-0.343, \quad p=0.074 ;$ Fig. 5) Invertebrate abundance in both the benthic and hyporheic zones contributed to this overall pattern, but the relationship was most pronounced in the benthic sediments (Fig. 5).

\section{Discussion}

Flow recession and low flows in the River Lathkill and River Glen provided an opportunity to examine benthic invertebrate use of the hyporheic refugium during conditions preceding the dry phase in temporary streams. Considering multiple sites across two rivers facilitated
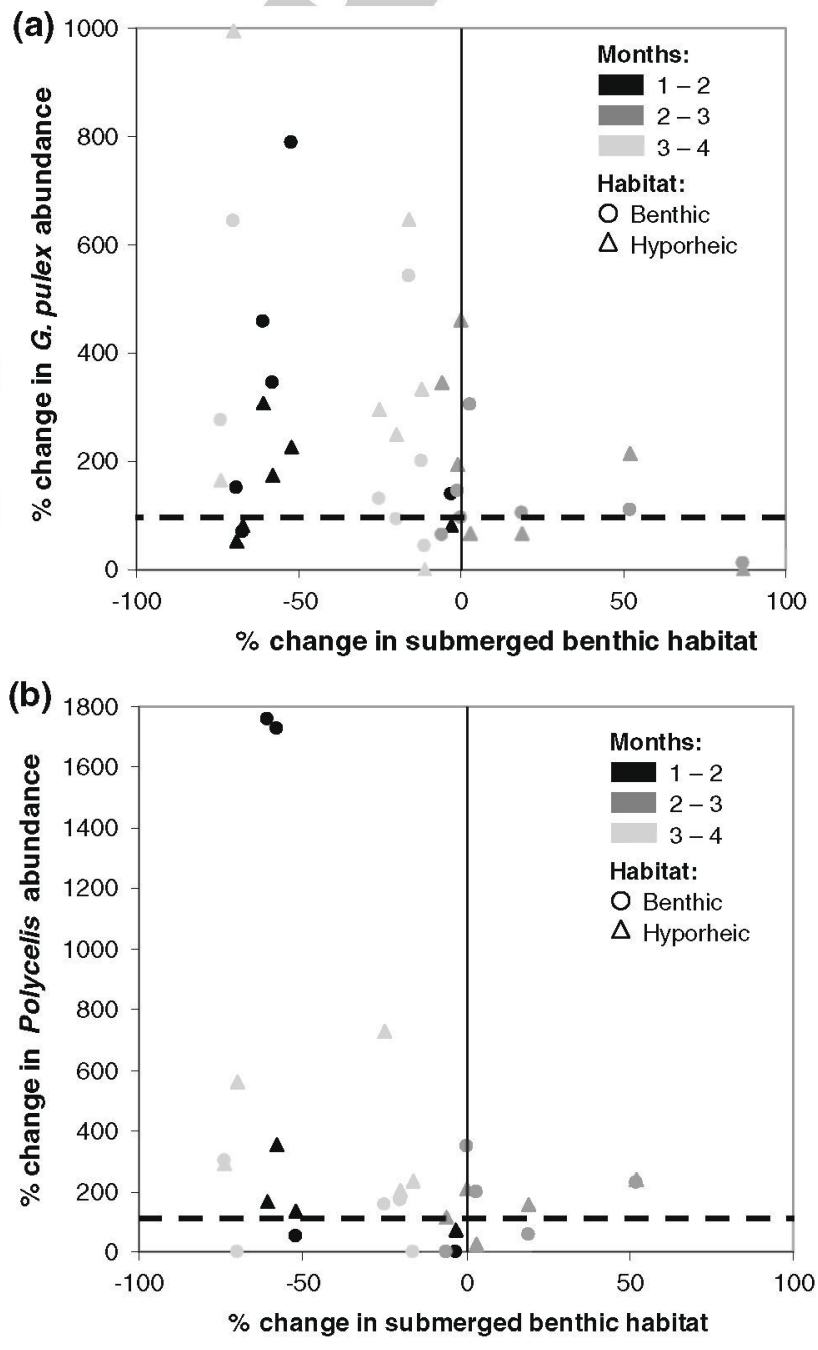

Fig. 5 Percentage change in invertebrate abundance in the benthic and hyporheic zones in relation to monthly changes in the availability of submerged benthic habitat: a Gammanus pulex; b Polycelis spp. Dashed lines indicate $100 \%$ of abundance recorded in the previous month i.e. no change

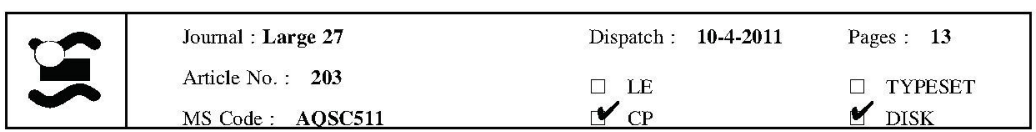


467 examination of spatial variability in the general patterns of 468 refugium use reported by Stubbington et al. (2011).

Invertebrate abundance in the benthic sediments

Differences in bed morphology resulted in site-specific extent and timing of habitat contraction (Table 1). Reductions in benthic habitat availability were associated with increases in the abundance (i.e. population densities) of benthic invertebrates (Fig. 5), as noted by previous studies (Fritz and Dodds 2004; James et al. 2008). In both rivers, taxa that increased in abundance included dominant, competitive species with the potential to increase biotic interactions. In particular, G. pulex is able to outcompete other taxa for resources (Hynes 1954; Graça et al. 1993) and is a generalist feeder with predatory and cannibalistic components in its diet (Dick 1995; Kelly et al. 2002). Peak G. pulex benthic densities were high $\left(2,200-6,400 \mathrm{~m}^{-2}\right.$ at all Lathkill sites; cf. Mortensen 1982; Crane 1994), representing conditions of considerable biotic risk for vulnerable individuals. Polycelis spp. are also predatory and consume taxa including Gammarus (Reynoldson 1981). P. felina reached particularly high abundance at Lathkill $1\left(>3,100 \mathrm{~m}^{-2}\right)$, adding to the proposed increase in biotic interactions.

\section{Distinguishing between active and passive refugium} use

Previous studies have been inconsistent in their definition of 'refugium use'. Some studies have reported an increase in the numerical abundance of a benthic taxon as evidence of active migrations into deeper sediments (e.g. Williams and Hynes 1974; Clinton et al. 1996); however, this may reflect only passive dispersal of an expanding benthic population. Other research has considered an increase in the hyporheic proportion of a taxon's total (benthic + hyporheic) population as evidence of refugium use (e.g. Griffith and Perry 1993; Fenoglio et al. 2006). However, an increase in the hyporheic proportion may be concurrent with a reduction in hyporheic abundance, so long as the latter decline is of a lesser magnitude than occurs in the benthic sediments; again, such refugium use is only passive. Therefore, the most compelling evidence of active refugium use (i.e. shelter-seeking behaviour) is provided by concurrent increases in a taxon's hyporheic abundance and the hyporheic proportion of that taxon's total population (Wood et al. 2010).

\section{Spatial variability in use of the hyporheic refugium}

Habitat contraction did not affect the spatial extent of the $\mathrm{HZ}$, which was therefore a potential refugium from increasing biotic interactions in the benthic sediments. Evidence of refugium use, as defined above, was recorded for G. pulex at Lathkill 2, 3 and 5. Refugial potential at these sites varied, being reduced by a high proportion of fine sediment at Lathkill 2 and 5, and further reduced by low DO concentrations at Lathkill 5 (Table 4). However, G. pulex can tolerate oxygen concentrations below the mean values recorded (Maltby 1995), and is able to burrow into fine sediments (Ward 1986). In addition, downwelling water dominated hydrologic exchange at these three sites, which may have promoted refugium use: firstly, the direction of water movement potentially facilitated both passive and active downwards migrations, and secondly, the influence of surface water on water chemistry increased suitability of the hydrological environment for benthic taxa (cf. Datry et al. 2007). Evidence of active refugium use was not, however, observed at two other sites dominated by downwelling water: Lathkill 4 and Glen 2. At Lathkill 4, this was due to an increase in the hyporheic abundance of G. pulex coinciding with a more pronounced increase in benthic abundance (Fig. 3); a concurrent increase in hyporheic proportion was restricted to a single sampling point. Similarly, a substantial reduction in habitat availability at Glen 2 between months 1 and 2 (Table 1) was accompanied by both a sevenfold increase in the hyporheic abundance of $G$. pulex and a fourfold increase in benthic abundance; the hyporheic proportion therefore increased only slightly (Fig. 3). At both sites, some active migration into the $\mathrm{HZ}$ may have occurred, but evidence is equivocal.

The hyporheic abundance of $G$. pulex remained very similar in all months at Lathkill 1, despite considerable habitat contraction and very high benthic population densities (Fig. 3; Table 1). Whilst Gammarus species are known to exhibit positive rheotaxis (e.g. Elser 2001), energetic costs of long-term position maintenance are likely to be relatively high in upwelling water. In addition, low DO concentrations (Table 4) may have discouraged hyporheic refugium use by $G$. pulex; whilst the taxon can tolerate such conditions, experimental work has shown that Gammarus species actively migrate into regions of higher oxygen availability (Henry and Danielopol 1999). In contrast to G. pulex, P. felina increased in abundance in the $\mathrm{HZ}$ of Lathkill 1 in months 3 and 4. This taxon is common in groundwater dominated streams (Rada and Puljas 2010), can tolerate very low oxygen concentrations (RussierDelolme 1974) and is morphologically suited to inhabit interstices, and was therefore better equipped to exploit the $\mathrm{HZ}$.

The observed spatial variability in refugium use may also reflect factors not characterised by the current study, for example hyporheic flow velocities (which should not be assumed to be proportional to surface flow velocities; Wagner and Bretschko 2002) and hyporheic sediment

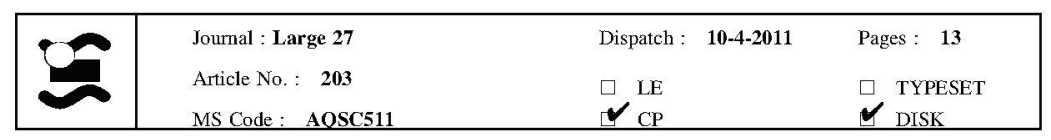


porosity (Maridet and Philippe 1995). Particulate and dissolved organic carbon, nitrate and phosphate concentrations were quantified in surface water and at all hyporheic depths but did not exhibit significant temporal change or have significant relationships with hyporheic invertebrate community parameters (data not presented; cf. Strayer et al. 1997; Davy-Bowker et al. 2006).

Seasonal changes in the abundance of $G$. pulex and Polycelis spp. can be discounted for two reasons. Firstly, the four-month sampling programme was repeated at Lathkill 5 in a second year, when no reduction in habitat availability occurred. During this period, neither the benthic abundance, hyporheic abundance, nor the hyporheic proportion of either taxon changed significantly between months. Secondly, whilst measuring the body size of hyporheic inhabitants was not justified due to the size bias of the pump sampling methodology, personal observations indicated that no discernable change in the proportion of small individuals accompanied increases in the abundance of either G. pulex or Polycelis spp. Both of these observations support the suggestion that temporal changes in abundance were linked to habitat availability rather than seasonal population dynamics.

A conceptual model of hyporheic refugium use during low flows

Patterns observed in the Lathkill and Glen have facilitated development of a conceptual model describing environmental factors controlling $\mathrm{HZ}$ refugium use as flow declines (Fig. 6). Variable bed morphology results in spatial variability in the extent of benthic habitat contraction during flow recession. Any reduction in habitat availability is inversely related to an increase in benthic population densities as mobile taxa become concentrated into a smaller space. Density-dependent biotic interactions (e.g. competition, predation, cannibalism) increase biotic risks, particularly for vulnerable groups (e.g. juveniles and individuals at moult; Dick 1995; McGrath et al. 2007). The HZ is a potential refugium from these biotic pressures due to lower population densities (Williams and Hynes 1974; Davy-Bowker et al. 2006) and reduced predation efficiency. However, the results of this study suggest that the refugial potential of the $\mathrm{HZ}$ is spatially variable due to heterogeneity in environmental parameters. The direction of hydrologic exchange is of particular importance, with upwelling water lowering refugial potential, possibly due to higher energetic costs (long-term position maintenance against the direction of flow) in a resource-poor environment (low oxygen, reduced allochthonous inputs). In contrast, downwelling water facilitates refugium use, with the direction of flow providing physical forces that promote downward migrations as well as inputs of organic matter and oxygen (Dole-Olivier et al. 1997; Fig. 6). In both upwelling and downwelling zones, refugial potential may also be influenced by factors such as sediment composition, with fine sediments clogging interstices and preventing inhabitation (Belaidi et al. 2004; Olsen and Townsend 2005).

\section{Temporal variability in the hyporheic refugium}

Benthic invertebrates entering the $\mathrm{HZ}$ during habitat contraction appear ideally placed to persist during any subsequent dry phase in temporary streams. However, the long-term survival of low-flow refugees following surface
Fig. 6 Spatial variability in the refugial potential of the hyporheic zone (HZ) during flow recession and low flows, in relation to the direction of hydrologic exchange

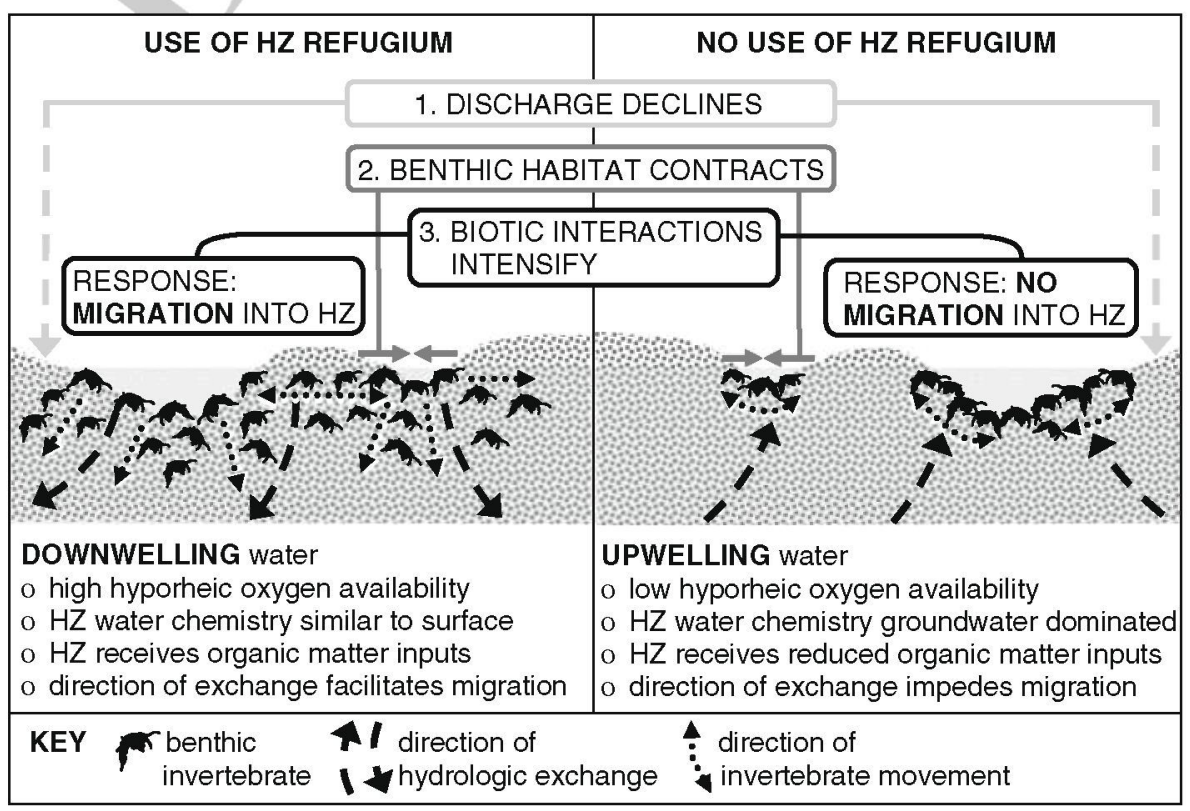

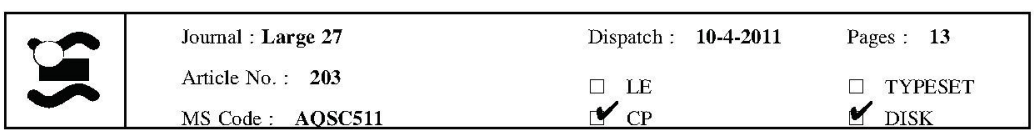


drying remains uncertain. At Glen 2, where short duration streambed drying occurred between months 2-3 and 3-4, hyporheic abundance of $G$. pulex and Polycelis tenuis was extremely low following drying events despite their previous inhabitation of the $\mathrm{HZ}$ during habitat contraction (Fig. 3). This highlights additional variability in the HZ's ability to function as a refugium: refugial potential may vary temporally in response to changing environmental conditions (Stubbington et al. 2009a). Hyporheic sediments were not characterised during the dry phase at Glen 2. However, the proportion of fine sediment was high at this site (Table 4) and may have peaked due to deposition as flow declined and ceased (Belaidi et al. 2004); hyporheic DO concentrations were low in month 3 (Table 3 ) and were probably further reduced during dry phases (Smock et al. 1994); and the responsiveness of this losing reach may have resulted in the loss of interstitial free water from the shallow hyporheic sediments (Boulton and Stanley 1995; Maddock et al. 1995). Any one of these temporally variable factors would be sufficient to explain low hyporheic abundance of $G$. pulex and $P$. tenuis between dry phases.

An assumption underlying all tests of the hyporheic refuge hypothesis is that refugees are able to recolonise the benthic sediments after a disturbance and complete their lifecycle (Lancaster and Belyea 1997). However, the low benthic and hyporheic abundance of both $G$. pulex and $P$. tenuis following short duration drying events at Glen 2 highlights a limitation of all investigations of the $\mathrm{HZ}$ refugium conducted to date: the return of hyporheic refugees to the benthic sediments has not been demonstrated (Dole-Olivier et al. 1997). Whilst the ability of invertebrates including $G$. pulex to migrate through the sediments in both vertical directions is known (Elser 2001; Bo et al. 2006), further studies are required to confirm the mid- to long-term survival prospects of hyporheic refugees. As technologies become available, future field and experimental research should attempt to track individual invertebrates, to ascertain how vertical positioning changes in response to hydrological variability (Whitfield-Gibbons and Andrews 2004). Multi-dimensional cage traps (see Elser 2001) may also prove fruitful in investigation of small-scale directional invertebrate movements. In the meantime, irrefutable evidence of the $\mathrm{HZ}$ as true refugium promoting long-term survival remains elusive.

\section{Conclusion}

The paired benthic-hyporheic sampling approach adopted in the current study was effective in identifying spatial variability, temporal variability and taxon specificity in hyporheic refugium use. Habitat contraction, benthic population changes and consequent refugium use were found to vary both within and between sites, an unsurprising observation given the widely recognised heterogeneity of instream habitats. This inherent patchiness makes the $\mathrm{HZ}$ a vital component of a range of instream refugia with the potential to promote long-term invertebrate persistence during habitat contraction and subsequent dry phases in temporary streams. Climate change scenarios predict an increasing drought frequency in many regions, with consequent shifts from perennial to intermittent flow likely in some systems; these climatic changes are likely to be accompanied by increasing pressures on limited water resources (Davies 2010; Larned et al. 2010). Therefore, the importance of the $\mathrm{HZ}$ as a refugial habitat is set to increase. However, the integrity of the $\mathrm{HZ}$ habitat is increasingly threatened by anthropogenic activities that deposit fine sediment in fluvial ecosystems, potentially clogging hyporheic interstices, compromising hydrologic exchange and reducing refugial potential (Hancock 2002), particularly in downwelling areas. By highlighting the particular importance of these downwelling zones as potential refugia, this study has drawn attention to the need for sensitive management strategies that recognise the importance of the $\mathrm{HZ}$ in invertebrate persistence and take rehabilitative action where appropriate.

Acknowledgments RS acknowledges the support of a Loughborough University faculty studentship. Grateful thanks to Patrick Byrne, Matthew Johnson, Jonny Lewis, Sally Little, Antonia Liversidge, Matthew Mohammed, Jules Toone and Tom Worrall for assistance in the field. Thanks also to Philip Bowler (Natural England) and to Chris Extence and Richard Chadd (Environment Agency) for advice and site access on the River Lathkill and River Glen, respectively. River discharge data were generously provided by John Gunn (University of Birmingham) and Ian Gray (Environment Agency). We also extend our thanks to two anonymous reviewers, whose insightful comments greatly improved this manuscript.

\section{References}

Belaidi N, Taleb A, Gagneur J (2004) Composition and dynamics of hyporheic and surface fauna in relation to the management of a polluted reservoir. Int J Lim 40:237-248. doi:10.1051/limn/ 2004020

Bo T, Cucco M, Fenoglio S, Malacarne G (2006) Colonisation patterns and vertical movements of stream invertebrates in the interstitial zone: a case study in the Apennines, NW Italy. Hydrobiol 568:1573-5117. doi:10.1007/s 10750-006-0025-3

Boulton AJ (1989) Over-summering refuges of aquatic macroinvertebrates in two intermittent streams in central Victoria. T Roy Soc South Aust 113:23-34

Boulton AJ (2007) Field methods for monitoring surface/groundwater hydroecological interactions in aquatic systems. In: Wood PJ, Hannah DM, Sadler JP (eds) Hydroecology and ecohydrology past, present and future. Wiley, Chichester, pp 147-164

Boulton AJ, Stanley EH (1995) Hyporheic processes during flooding and drying in a Sonoran Desert stream. II. Faunal dynamics. Arch Hydrobiol 134:27-52

\begin{tabular}{|l|lll|}
\hline Journal : Large 27 & Dispatch : 10-4-2011 & Pages : 13 \\
Article No.: 203 & $\square$ LE & $\square$ TYPESET \\
MS Code : AOSC511 & $\checkmark_{\mathrm{CP}}$ & $\checkmark$ DISK \\
\hline
\end{tabular}


British Atmospheric Data Centre (BADC) (2009) Met OfficeMIDAS land surface station data. British Atmospheric Data Centre. http://badc.nerc.ac.uk/data/. Accessed 14th Nov 2009

Bunte K, Abt SR (2001) Sampling surface and subsurface particle size distributions in wadable gravel- and cobble-bed streams for analyses in sediment transport, hydraulics and streambed monitoring. General Technical Report RMRS-GTR-74, Department of Agriculture Forest Service, United States

Clinton SM, Grimm NB, Fisher SG (1996) Response of a hyporheic invertebrate assemblage to drying disturbance in a desert stream. J N Am Benthol Soc 15:700-712

Cooling MP, Boulton AJ (1993) Aspects of the hyporheic zone below the terminus of a South Australian arid-zone stream. Aust J Mar Fresh Res 44:411-426

Covich AP, Crowl TA, Scatena FN (2003) Effects of extreme low flows on freshwater shrimps in a perennial tropical stream. Freshw Biol 48:1199-1206. doi:10.1046/j.1365-2427.2003. 01093.x

Cowx IG, Young WO, Hellawell JM (1984) The influence of drought on the fish and invertebrate populations of an upland stream in Wales. Freshw Biol 14:165-177

Crane M (1994) Population characteristics of Gammarus pulex (L.) from five English streams. Hydrobiol 281:91-100. doi:10.1007/ BF00006438

Datry T, Larned S, Scarsbrook M (2007) Responses of hyporheic invertebrate assemblages to large-scale variation in flow permanence and surface-subsurface exchange. Freshw Biol 52:1452-1462. doi: $10.1111 / \mathrm{j} .1365-2427.2007 .01775 . \mathrm{x}$

Datry T, Lafont M, Larned ST (2010) Hyporheic annelid distribution along a flow permanence gradient in an alluvial river. Aquat Sci 72:335-346. doi: $10.1007 /$ s00027-010-0139-6

Davies PM (2010) Climate change implications for river restoration in global biodiversity hotspots. Restor Ecol 18:261-268. doi: 10.1111/j.1526-100X.2009.00648.x

Davy-Bowker J, Sweeting W, Wright N, Clarke RT, Arnott S (2006) The distribution of benthic and hyporheic macroinvertebrates from the heads and tails of riffles. Hydrobiol 563:109-123. doi: $10.1007 / \mathrm{s} 10750-005-1482-9$

Del Rosario RB, Resh VH (2000) Invertebrates in intermittent and perennial streams: is the hyporheic zone a refuge from drying? J N Am Benthol Soc 19:680-696

Dewson ZS, Death RG, James ABW (2003) The effect of water abstractions on invertebrate communities in four small North Island streams. N Z Nat Sci 28:51-65. doi:10.1899/07-003R.1

Dick JTA (1995) The cannibalistic behaviour of two Gammarus species (Crustacea: Amphipoda). J Zool 236:697-706

Dole-Olivier M-J, Marmonier P, Beffy JL (1997) Response of invertebrates to lotic disturbance: is the hyporheic zone a patchy refugium? Freshw Biol 37:257-276. doi:10.1046/j.1365-2427.1997.00140.x

Elser P (2001) Assessing small-scale directional movements of benthic invertebrates in streams by using a multidirectional cage trap. Limnologica 31:119-128. doi:10.1016/S0075-9511(01) 80006-2

Fenoglio S, Bo T, Bosi G (2006) Deep interstitial habitat as a refuge for Agabus paludosus (Fabricus) (Coleoptera: Dytiscidae) during summer droughts. Coleopterists Bull 60:37-41

Fraser BG, Williams DD (1997) Accuracy and precision in sampling hyporheic fauna. Can J Fish Aquat Sci 54:1135-1141. doi: $10.1139 /$ cjfas-54-5-1135

Fritz KM, Dodds WK (2004) Resistance and resilience of macroinvertebrate assemblages to drying and flood in a tallgrass prairie stream system. Hydrobiol 527:99-112. doi:10.1023/B:HYDR. $0000043188.53497 .9 \mathrm{~B}$

Graça MAS, Maltby L, Calow P (1993) Importance of fungi in the diet of Gammarus pulex and Asellus aquaticus. Oecologia 96:304-309
Griffith MB, Perry SA (1993) The distribution of macroinvertebrates in the hyporheic zone of two small Appalachian headwater streams. Arch Hydrobiol 126:373-384

Hancock PJ (2002) Human impacts on the stream-groundwater exchange zone. Environ Manage 29:763-781. doi:10.1007/s00267001-0064-5

Hancock PJ (2006) The response of hyporheic invertebrate communities to a large flood in the Hunter River, New South Wales. Hydrobiol 568:255-262. doi:10.1007/s 10750-006-0110-7

Henry KS, Danielopol DL (1999) Oxygen dependent habitat selection in surface and hyporheic environments by Gammarus roeseli Gervais (Crustacea, Amphipoda): experimental evidence. Hydrobiol 390:51-60. doi:10.1023/A:1003541300460

Holomuzki JR, Feminella JW, Power ME (2010) Biotic interactions in freshwater benthic habitats. J N Am Benthol Soc 29:220-244. doi: 10.1899/08-044.1

Hynes HBN (1954) The occurrence of Gammarus duebeni Lilljeborg and its occurrence in fresh water in western Britain. $\mathbf{J}$ Anim Ecol 23:38-84

James ABW, Dewson ZS, Death RG (2008) Do stream macroinvertebrates use instream refugia in response to severe short-term flow reduction in New Zealand streams? Freshw Biol 53:1316-1334. doi:10.1111/j.1365-2427.2008.01969.x

Kelly DW, Dick JTA, Montgomery WI (2002) The functional role of Gammarus (Crustacea: Amphipoda): shredders, predators, or both? Hydrobiol 485:199-203. doi:10.1023/A:1021370405349

Lancaster J, Belyea LR (1997) Nested hierarchies and scaledependence of mechanisms of flow refugium use. J N Am Benthol Soc 16:221-238

Larned ST, Datry T, Arscott DB, Tockner K (2010) Emerging concepts in temporary-river ecology. Freshw Biol 55:717-738. doi: $10.1111 / j .1365-2427.2009 .02322 . x$

Maddock I, Petts G, Bickerton M (1995) River channel assessmenta method for defining channel sectors on the River Glen, Lincolnshire, UK. In: Proceedings of Boulder symposium, July 1995. IAHS Publication no., vol 230. pp 219-226

Maltby L (1995) Sensitivity of the crustaceans Gammarus pulex (L.) and Asellus aquaticus (L.) to short-term exposure to hypoxia and unionized ammonia: observations and possible mechanisms. Wat Res 29:781-787. doi:10.1016/0043-1354(94)00231-U

Maridet L, Philippe M (1995) Influence of substrate characteristics on the vertical distribution of stream macroinvertebrates in the hyporheic zone. Folia Fac Sci Nat Univ Masarykianae Brunensis Biologia 21:101-105

McGrath KE, Peeters ETHM, Beijer JAJ, Scheffer M (2007) Habitatmediated cannibalism and microhabitat restriction in the stream invertebrate Gammarus pulex. Hydrobiol 589:155-164. doi: $10.1007 / \mathrm{s} 10750-007-0731-5$

Met Office (2009) Eastern England: climate Met Office. http://www.meto.gov.uk/climate/uk/ee/. Accessed 16th Oct 2009

Mortensen E (1982) Production of Gammarus pulex L. (Amphipoda) in a small Danish stream. Hydrobiol 87:77-82. doi:10.1007/ BF00016664

Olsen DA, Townsend CR (2005) Flood effects on invertebrates, sediments and particulate organic matter in the hyporheic zone of a gravel-bed stream. Freshw Biol 50:839-853. doi:10.1111/ j.1365-2427.2005.01365.x

Orghidan T (1959) Ein neuer lebensraum des unterirdischen wassers, der hyporheische biotope. Arch Hydrobiol 55:392-414

Orghidan T (2010) A new habitat of subsurface waters: the hyporheic biotope. Fund Appl Limnol 176:291-302. doi:10.1127/18639135/2010/0176-0291

Palmer MA (1993) Experimentation in the hyporheic zone: challenges and prospectus. J N Am Benthol Soc 12:84-93

Puig MA, Sabater F, Malo J (1990) Benthic and hyporheic faunas of mayflies and stoneflies in the Ter river basin (NE-Spain). In:
800

801

802

803

804

805

806

807

808

809

810

811

812

813

814

815

816

817

818

819

820

821

822

823

824

825

826

827

828

829

830

831

832

833

834

835

836

837

838

839

840

841

842

843

844

845

846

847

848

849

850

851

852

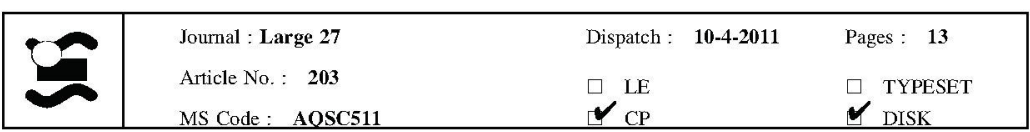


Campbell IC (ed) Mayflies and stoneflies: life histories and biology. Kluwer Academic Publishers, Dordrecht, pp 255-257

Rada B, Puljas S (2010) Do karst rivers "deserve" their own biotic index? A ten year study on macrozoobenthos in Croatia. Int $\mathbf{J}$ Speleol 39:137-147

Reynoldson TB (1981) The ecology of the Turbellaria with special reference to the freshwater triclads. Hydrobiol 84:87-90. doi: $10.1007 / \mathrm{BF} 00026166$

Rice S (1995) The spatial variation and routine sampling of spawning gravels in small coastal streams. British Columbia Ministry of Forests, Victoria, British Columbia. Working Paper 06/1995

Richards C, Bacon KL (1994) Influence of fine sediment on macroinvertebrate colonization of surface and hyporheic stream substrates. West N Am Naturalist 54:106-113

Robertson AL, Wood PJ (2010) Ecology of the hyporheic zone: origins, current knowledge and future directions. Fund Appl Limnol 176:279-289. doi:10.1127/1863-9135/2010/0176-0279

Russier-Delolme R (1974) A comparative study of the tolerance of two freshwater planarians, Dugesia tigrina and Polycelis felina, to low oxygen levels. Int J Lim 10:311-322

Savage AA (1996) Density dependent and density independent relationships during a twenty-seven year study of the population dynamics of the benthic macroinvertebrate community of a chemically unstable lake. Hydrobiol 335:115-131. doi:10.1007/ BF00015273

Scarsbrook MR, Halliday J (2002) Detecting patterns in hyporheic community structure: does sampling method alter the story? New Zeal J Mar Fresh 36:443-453

Smock LA, Smith LC, Jones JB Jr, Hooper SM (1994) Effects of drought and a hurricane on a coastal headwater stream. Arch Hydrobiol 131:25-38

Strayer DL, May SE, Nielsen P, Wollheim W, Hausam S (1997) Oxygen, organic matter and sediment granulometry as controls on hyporheic animal communities. Arch Hydrobiol 140:131-144

Stubbington R, Greenwood AM, Wood PJ, Armitage PD, Gunn J, Robertson AL (2009a) The response of perennial and temporary headwater stream invertebrate communities to hydrological extremes. Hydrobiol 630:299-312. doi:10.1007/s10750-009- 903 9823-8

Stubbington R, Wood PJ, Boulton AJ (2009b) Low flow controls on benthic and hyporheic macroinvertebrate assemblages during supra-seasonal drought. Hydrol Process 23:2252-2263. doi: 10.1002/hyp. 7290

Stubbington R, Wood PJ, Reid I, Gunn, J (2011) Benthic and hyporheic invertebrate community responses to seasonal flow recession in a groundwater-dominated stream. Ecohydrology (early view). doi: $10.1002 /$ eco.168 (in press)

Wagner FH, Bretschko G (2002) Interstitial flow through preferential flow paths in the hyporheic zone of the Oberer Seeback, Austria. Aquat Sci 64:307-316. doi:10.1007/s00027-002-8075-8

Ward PI (1986) A comparative field study of the breeding behaviour of a stream and a pond population of Gammarus pulex (Amphipoda). Oikos 46:29-36

Weigelhofer G, Waringer J (2003) Vertical distribution of benthic macroinvertebrates in riffles versus deep runs with differing contents of fine sediments (Weidlingbach, Austria). Int Rev Hydrobiol 88:304-313

Whitfield-Gibbons J, Andrews KM (2004) PIT tagging: simple technology at its best. Bioscience 54:447-454. doi:10.1641/ 0006-3568(2004)054[0447:PTSTAI]2.0.CO;2

Williams DD, Hynes HBN (1974) The occurrence of benthos deep in the substratum of a stream. Freshw Biol 4:233-256

Winemiller KO, Flecker AS, Hoeinghaus DJ (2010) Patch dynamics and environmental heterogeneity in lotic ecosystems. J N Am Benthol Soc 29:84-99. doi:10.1899/08-048.1

Wood PJ, Gunn J, Smith H, Abas-Kutty A (2005) Flow permanence and macroinvertebrate community diversity within groundwater dominated headwater streams and springs. Hydrobiol 545:55-64. doi: $10.1007 / \mathrm{s} 10750-005-2213-y$

Wood PI, Boulton AJ, Little S, Stubbington R (2010) Is the hyporheic zone a refugium for macroinvertebrates during severe low flow conditions? Fund Appl Limnol 176:377-390. doi:10.1127/18639135/2010/0176-0377

\begin{tabular}{|l|lll|}
\hline & Journal : Large 27 & Dispatch : 10-4-2011 & Pages : 13 \\
Article No. : 203 & $\square$ LE & $\square$ TYPESET \\
MS Code : AOSC511 & $\sim_{\mathrm{CP}}$ & DISK $^{2}$ \\
\hline
\end{tabular}

